\title{
Does Red Bull give wings to vodka? Placebo effects of marketing labels on perceived intoxication and risky attitudes and behaviors $\hbar^{2}$
}

\author{
Yann Cornil $^{\mathrm{a}, *}$, Pierre Chandon ${ }^{\mathrm{b}}$, Aradhna Krishna ${ }^{\mathrm{c}}$ \\ ${ }^{a}$ Sauder School of Business, University of British Columbia, 2053 Main Mall, Vancouver, BC V6T 1Z2, Canada \\ ${ }^{\mathrm{b}}$ INSEAD, Boulevard de Constance, 77300 Fontainebleau, France \\ ${ }^{\mathrm{c}}$ Ross School of Business, University of Michigan, 701 Tappan Street, Ann Arbor, MI 48109-1234, United States
}

Accepted by Anirban Mukhopadhyay, Editor; Associate Editor, Tom Kramer

Received 16 February 2016; received in revised form 16 March 2017; accepted 20 March 2017

Available online 27 March 2017

\begin{abstract}
Why sexual assaults and car accidents are associated with the consumption of alcohol mixed with energy drinks (AMED) is still unclear. In a single study, we show that the label used to describe AMED cocktails can have causal non-pharmacological effects on consumers' perceived intoxication, attitudes, and behaviors. Young men who consumed a cocktail of fruit juice, vodka, and Red Bull felt more intoxicated, took more risks, were more sexually self-confident, but intended to wait longer before driving when the cocktail's label emphasized the presence of the energy drink (a "Vodka-Red Bull cocktail") compared to when it did not (a "Vodka" or "Exotic fruits" cocktail). Speaking to the process underlying these placebo effects, we found no moderation of experience but a strong interaction with expectations: These effects were stronger for people who believe that energy drinks boost alcohol intoxication and who believe that intoxication increases impulsiveness, reduces sexual inhibition, and weakens reflexes. These findings have implications for understanding marketing placebo effects and for the pressing debate on the regulation of the marketing of energy drinks.
\end{abstract}

(C) 2017 Society for Consumer Psychology. Published by Elsevier Inc. All rights reserved.

Keywords: Expectations; Placebo effects; Alcohol; Energy drink; Public health; Sensory marketing

Red Bull recently settled a $\$ 13 \mathrm{M}$ class action lawsuit brought by plaintiffs who argued that it does false advertising and does not "give wings" as it proclaims (Careathers v. Red Bull GmBh, 2016). The case was especially noteworthy

\footnotetext{
is We thank Quentin André, Huong Ngo, Nicolas Manoharan, and Liselott Pettersson from the INSEAD Sorbonne University Behavioral Lab for their great research assistance.

* Corresponding author.

E-mail addresses: yann.cornil@sauder.ubc.ca (Y. Cornil), pierre.chandon@insead.edu (P. Chandon), aradhna@umich.edu (A. Krishna).

is We thank Quentin André, Huong Ngo, Nicolas Manoharan, and Liselott Pettersson from the INSEAD Sorbonne University Behavioral Lab for their great research assistance.
}

because Alcohol Mixed with Energy Drinks (AMED), such as Red Bull, are consumed by $50 \%$ of American and European college students and are associated with numerous anti-social behaviors (Miller, 2013). Compared to people who drink alcohol straight, those who mix it with energy drinks have double the risk of experiencing or committing sexual assault, or having an alcohol-related motor vehicle crash (Howland \& Rohsenow, 2013). The court in this case did not consider the psychological effects that energy drinks may have, especially when mixed with alcohol; however, we do.

Prior consumer behavior research has shown that marketing actions can result in "placebo effects" (for a review, Plassmann \& Wagner, 2014). For instance, energy drink prices, logos, and labels can impact puzzle solving, physical reflexes, and video 
car racing (Brasel \& Gips, 2011; Irmak, Block, \& Fitzsimons, 2005; Shiv, Carmon, \& Ariely, 2005).

We extend this stream of research to examine the perceptual, attitudinal, and behavioral placebo effects created by the labeling of AMED. We show that merely emphasizing the presence of an energy drink in the label used for the AMED (e.g., calling it a "vodka-Red Bull" instead of a "vodka" or "exotic fruits" cocktail) makes young males feel more intoxicated, take more risk in a gambling game, be more sexually self-confident, but also more likely to wait before driving.

Our study contributes to the pressing debate on possible reasons for the empirical link between AMED consumption and risky attitudes and behaviors. Crucially, our study reflects realistic AMED consumption situations-subjects consume real alcohol - we merely change the label of the drink. Finally, we contribute to the debate on the source of marketing placebo effects - expectancy or conditioning - by examining the moderating effects of beliefs and past experience (Stewart-Williams \& Podd, 2004).

\section{Explaining the link between AMED consumption, per- ceived intoxication, and risky attitudes and behaviors}

\section{Perceived intoxication: physiological vs. placebo effects}

Early AMED studies argued that the caffeine amounts present in energy drinks can mask drinkers' perception of being intoxicated, without attenuating the diminishing effects of alcohol on mental and physical abilities, resulting in inconsiderate risk-taking (FDA, 2010; Howland \& Rohsenow, 2013).

However, recently, there has been converging evidence against the masking theory. A meta-analysis of 16 "blind" experiments (in which people are not told what they are drinking) concluded that the low amount of caffeine typical of AMED has no effect on actual or perceived intoxication and is unlikely to increase alcohol's effect on behavior (Benson, Verster, Alford, \& Scholey, 2014). The current thinking is that the link between AMED consumption and risky behaviors is spurious and caused by self-selection, because people who drink AMED are inherently risk seekers (EFSA, 2015; Skeen \& Glenn, 2011; Verster, Aufricht, \& Alford, 2012).

We propose an alternate psychological (vs. physiological) causal explanation for the link between AMED and risky attitudes, in line with research on marketing placebo effects. In prior studies on AMED consumption, people did not know what they were drinking. Yet, in real life, people know what they are drinking. Additionally, college students believe that adding an energy drink to alcohol increases alcohol intoxication, compared to drinking the same amount of alcohol straight (Marczinski, Fillmore, Bardgett, \& Howard, 2011; Peacock, Bruno, \& Martin, 2013). We therefore hypothesize that labeling an AMED cocktail to emphasize the presence of an energy drink will lead to higher perceived intoxication (Hypothesis 1a).

\section{The moderating role of beliefs and experience}

Placebo effects can be caused by explicit beliefs created by information or observation (the "expectancy theory" of placebo effects), but also by conditioned responses created by experience (the "conditioning" theory of placebo effects). Generally, these two sources reinforce each other (Stewart-Williams \& Podd, 2004). In the pain domain for example, the placebo effects of analgesics last longer when they are induced by a large number of conditioning trials (Colloca, Petrovic, Wager, Ingvar, \& Benedetti, 2010). However, it has not been tested if marketing placebo effects can rely solely on beliefs (for instance created by marketing and media communication), even when these beliefs are not backed by past consumption experiences.

AMED consumption is particularly suited to answer this question because of the dissociation between beliefs and experience. As reviewed earlier, people do not feel more intoxicated after consuming AMED vs. straight alcohol when they do not know what they are drinking (Benson et al., 2014). Yet, a majority of students explicitly believe that energy drinks boost the intoxicating effects of alcohol (Marczinski et al., 2011; Peacock et al., 2013). We therefore hypothesize that the placebo effects of labels on perceived intoxication are only moderated by the belief that energy drinks increase alcohol intoxication (Hypothesis 1b), and are independent of past intoxication experience. Supporting H1b, Shiv et al. (2005) found that prior consumption did not moderate the effect of energy drink pricing on people's ability to solve puzzles. However, they only measured prior consumption of the specific energy drink brand used in the study, not prior experience with solving puzzles (with and without energy drink consumption).

\section{Placebo effects of energy drink labels on attitudes and behaviors}

Several studies have found that people explicitly associate alcohol intoxication with impulsiveness and risk-taking (e.g. Corazzini, Filippin, \& Vanin, 2014; Fromme, Katz, \& D'Amico, 1997a; Fromme, Katz, \& Rivet, 1997b) as well as with sexual disinhibition (George \& Stoner, 2000; Hull \& Bond, 1986). For instance, men feel more self-confident when talking to women when they believe that they have consumed alcohol (Bègue, Bushman, Zerhouni, Subra, \& Ourabah, 2013). Although people do associate alcohol intoxication with impulsiveness, they also associate it with cognitive and motor impairment, such as decreased reflexes. This is why studies consistently find that higher perceived intoxication (holding actual intoxication constant) leads to lower intentions to drive (Beirness, 1987; Quinn \& Fromme, 2012).

We hypothesize that emphasizing the presence of an Energy Drink in an AMED cocktail will increase risk-taking (Hypothesis 2a). We further expect that this effect will be stronger among people who jointly believe that energy drinks increase alcohol intoxication, and that alcohol intoxication increases impulsive decision-making $(H 2 b)$. 
Similarly, we hypothesize that emphasizing the presence of an Energy Drink will increase sexual self-confidence $(H 3 a)$, and that this effect will be stronger among people who jointly believe that energy drinks increase alcohol intoxication, and that alcohol intoxication increases sexual disinhibition $(H 3 b)$.

Finally, we hypothesize that emphasizing the presence of an Energy Drink will increase intentions to wait before driving (H4a), and that this effect will be stronger among people who jointly believe that energy drinks increase alcohol intoxication, and that alcohol intoxication weakens reflexes $(H 4 b)$.

\section{Method}

\section{Procedure}

We recruited participants by posting flyers and by emailing members of a research pool in Paris, France. Participants were prescreened through an online survey which included the Alcohol Use Disorders Identification Test (AUDIT) (Saunders, Aasland, Babor, \& Grant, 1993). Following the ethical research guidelines of the American National Institute on Alcohol Abuse and Alcoholism, we selected social drinkers with no risk of alcohol dependence (see Methodological Appendix for details). We also selected heterosexual men, because one of our variables of interest was male sexual self-confidence toward women, and participants with a Body Mass Index between 18 and 25 , to limit heterogeneity in actual alcohol intoxication. After the screening, we were left with 154 participants.

Participants signed a consent form stipulating that we were studying the attitudes of young people in bars and that they would be paid at least $€ 10$ for their participation, which included drinking a cocktail containing alcohol and energy drink. We used a chilled cocktail containing $6 \mathrm{cl}$ of $40 \%$ Smirnoff ${ }^{\circledR}$ Vodka (a common amount), $8 \mathrm{cl}$ of Red Bull ${ }^{\circledR}$ Silver Edition energy drink, and $16 \mathrm{cl}$ of Caraïbos ${ }^{\circledR}$ Nectar Planteur (exotic fruit juice). The target blood alcohol concentration (BAC) was $0.045 \mathrm{~g} / \mathrm{dL}$ at the time of the main measurements, 15-20 min after the beginning of the study (NIAAA-NIH, 2014).

Participants were randomly assigned to one of three experimental conditions that manipulated the label used to describe the drink, before the actual drinking took place. The first condition emphasized the presence of alcohol and energy drink by labeling the drink as a "Vodka-Red Bull cocktail". The second condition emphasized only alcohol by referring to the drink as a "Vodka cocktail". The third condition emphasized neither alcohol nor energy drink by referring to the drink as an "Exotic fruits cocktail". The labels were non-deceptive (fruit juices contributed the most to the taste of the cocktail). They recreated a bar consumption situation, where the person mixing or buying the cocktail can selectively emphasize any of the ingredients of the cocktail.

Participants were asked to finish the cocktail within $10 \mathrm{~min}$ while watching the kind of music videos that is shown in bars. To disguise the purpose of the study and allow for the onset of alcohol effects, participants watched other music videos for six additional minutes after they were done drinking. After that, they undertook a series of tasks on the computer for about $30 \mathrm{~min}$.

\section{Measures}

A list of our measures is given in Table 1. The pre-screening survey measured participants' intoxication experience, by adding up the scores of the first three items of the AUDIT questionnaire (“AUDIT-C”; Bush, Kivlahan, McDonell, Fihn, \& Bradley, 1998). The survey also measured participants' beliefs about the effects of alcohol intoxication on reflexes (1 item), sexual disinhibition (2 items, $\mathrm{r}=.48)$, and impulsiveness ( 2 items, $\mathrm{r}=.62)$ using established alcohol expectancy questionnaires (Brown, Christiansen, \& Goldman, 1987; Leigh \& Stacy, 1993; Young \& Knight, 1989). Participants' responses to the pre-screening survey were matched to their responses to the main study. The prescreening survey included other measures, which were not used to test our hypotheses (see the Appendix).

In the main study (after drinking), we first measured sexual aggressiveness by translating and adapting into French an established scale (Ariely \& Loewenstein, 2006) composed of three questions (Cronbach's alpha $=.96$ ).

We measured sexual self-confidence in a series of vignettes describing the sexual and romantic socialization in bars. We showed the (male, heterosexual) participants, photos of 15 young women, one by one. We selected these photos based on a pre-test study so that 5 of the 15 women would be viewed as clearly attractive. After looking at each photo, the participants answered two questions measuring sexual self-confidence: (a) their intention to approach and "chat up" the attractive woman represented in the photo, and (b) their prediction of whether the attractive woman would "accept their advances" and share her phone number $(\mathrm{r}=.56)$. Participants also rated the attractiveness of all 15 women. A factor analysis (principal-component) with the three measures of sexual aggressiveness, and the two measures of sexual self-confidence, showed that the measures loaded two distinct factors.

We measured general risk taking with the Balloon Analogue Risk Task (BART) (Lejuez et al., 2002; Peacock, Bruno, \& Martin, 2012). In this task, in each of twenty trials, participants could earn additional money by pumping a virtual balloon. Each pump inflated the balloon and added money to a counter. Participants could cash-out before the balloon exploded or keep pumping at the risk that it would explode, resulting in the loss of the money accumulated on the trial. The balloons exploded after a random number of pumps. Risk-taking behavior was measured by the total number of pumps (not the number of exploded balloons or the total money accumulated, both of which are influenced by the random number generator).

We then measured people's perceived ability to drive by asking them how long they would wait (number of minutes) to "sober up" before driving (3 questions; Cronbach's alpha = .90). After that, we measured perceived intoxication (4 questions; Cronbach's alpha $=.86$ ) as well as the Belief that energy drinks increase alcohol intoxication.

As manipulation checks, we asked participants to evaluate whether they had perceived the presence of an "energy drink, such as Red Bull", the presence of alcohol, and to estimate the amount of alcohol in the drink. 
Table 1

Summary of measures.

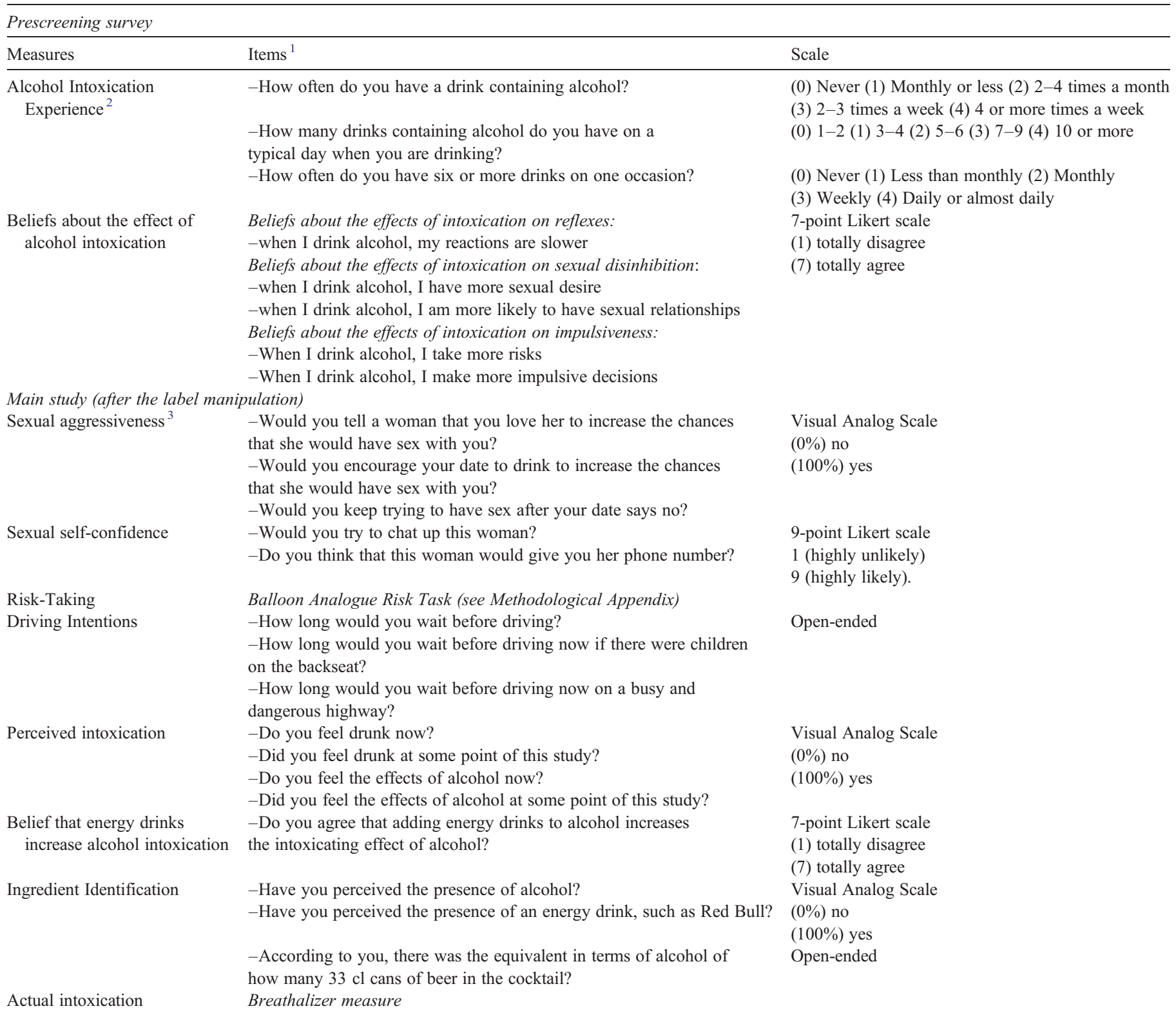

${ }^{1}$ French to English translation. See the Methodological Appendix for original versions.

2 AUDIC-C Questionnaire, Saunders et al. (1993).

3 Adapted from Ariely and Loewenstein (2006).

At the end of the experiment, we collected socio-demographic data and measured participants' actual blood alcohol concentration (BAC) with an electronic Breathalyzer. We allowed participants to leave the premises when their BAC reached $0.01 \mathrm{~g} / \mathrm{dL}$.

\section{Results}

\section{Manipulation checks}

An analysis of variance showed that actual intoxication (BAC level) did not vary across conditions $(p>.50)$. Most participants were able to identify the presence of alcohol $(M=$ $76.5 \%$ of the VAS scale, $S D=28.2 \%$ ), regardless of the labeling manipulation $(F(2151)=1.79, p=.17)$. Similarly, the perceived amount of alcohol (equivalent number of beer cans) was not influenced by the labeling manipulation $(p>.90)$. These results are consistent with prior studies which found that most people can tell if a drink contains alcohol or not, regardless of its label (Bègue et al., 2009).

On the other hand, labeling significantly influenced perceived energy drink presence $(F(2151)=28.02, p<.001)$. The perception that the cocktail contained an energy drink was significantly higher in the "Vodka-Red Bull" condition $(M=39.3 \%, S D=$ 

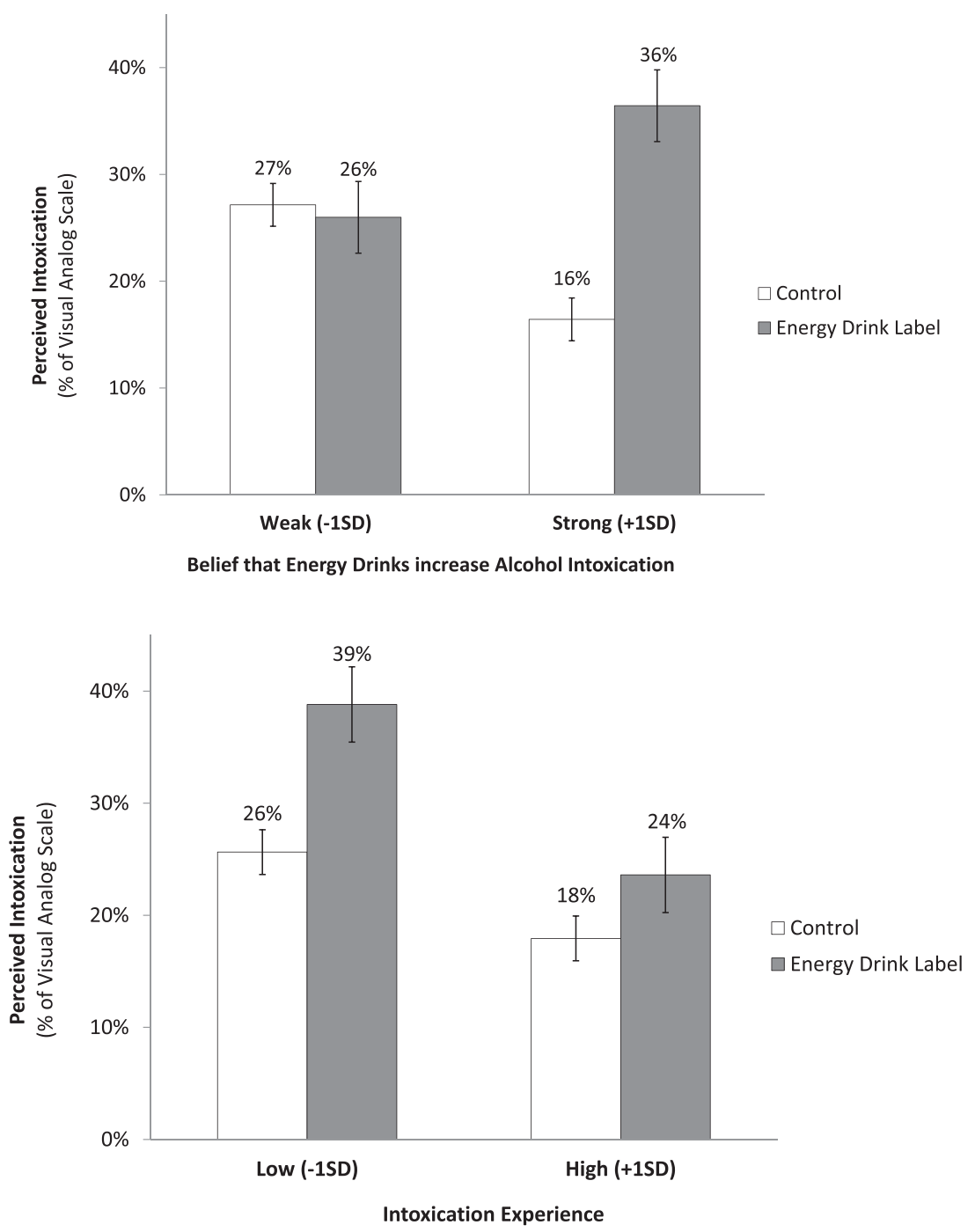

Fig. 1. Effects of energy drink label on perceived intoxication: moderation by beliefs and experience. Note: Perceived alcohol intoxication, measured on visual analogue scales, after drinking alcohol mixed with an energy drink. The chart shows the predicted effects of energy drink label for participants with a weak and strong Belief that energy drinks increase alcohol intoxication; and high and low levels of prior intoxication experience. Error bars denote standard errors.

$33.2 \%)$ than in the "Vodka" condition $(M=9.6 \%, S D=19.9 \%$, $F(1151)=38.7, p<.001)$, or the "Exotic fruits" condition $(M=$ $8.5 \%, S D=13.5 \%, F(1151)=43.4, p<.001)$.

Because all participants could identify the presence of alcohol, and because the labeling manipulation only influenced the identification of energy drink, we collapsed the "Exotic fruits" label and "Vodka" label conditions into a single control condition. The subsequent analyses therefore focus on examining the effect of a label that emphasizes (vs. does not emphasize) the presence of the energy drink. Analyses for all three conditions are provided in the Appendix.

\section{Perceived intoxication}

We regressed perceived intoxication on the Energy Drink Label manipulation, the mean-centered Belief that energy drinks increase alcohol intoxication, the mean-centered measure of intoxication experience, and their interaction with the label manipulation. Intoxication experience was not significantly correlated with the beliefs about energy drinks (see Appendix). Consistent with H1a, the Energy Drink label significantly increased perceived intoxication compared to the control condition $(t(148)=2.70, p=.008)$. Emphasizing the presence of Red Bull in the cocktail increased perceived intoxication by $51 \%$ (from $20 \%$ to $33 \%$ of the value-analogue scales). The main effect of the Belief that energy drinks increase alcohol intoxication was not significant $(p>.90)$, but its interaction with the label manipulation was significant $(t(148)=2.94, p=.004)$. As shown in Fig. 1, a spotlight analysis found that emphasizing the presence of Red Bull in the cocktail significantly increased the perceived intoxication of participants with a strong Belief that energy drinks increase alcohol intoxication (at 1SD above the average Belief, $t(148)=4.04, p<.001$ ), but had no effect among participants with a weak Belief (at 1SD below the average Belief, $p>$.86). 
Table 2

Attitudinal and Behavioral Effects: Moderated Regression Results (Unstandardized Coefficients and Standard Errors).

\begin{tabular}{|c|c|c|c|}
\hline & \multicolumn{3}{|c|}{ Attitudes and behavior } \\
\hline & Risk Taking & Sexual Self-Confidence & Sobering up before driving \\
\hline CONSTANT & $\begin{array}{l}96.65 \\
(2.49)\end{array}$ & $\begin{array}{l}4.44 \\
(.10)\end{array}$ & $\begin{array}{l}28.11 \\
(2.01)\end{array}$ \\
\hline ED_LABEL & $\begin{array}{l}5.16^{* *} \\
(2.49)\end{array}$ & $\begin{array}{l}.21 * * \\
(.10)\end{array}$ & $\begin{array}{l}4.85 * * \\
(2.01)\end{array}$ \\
\hline $\mathrm{ED} \rightarrow$ INTOX_BELIEF & $\begin{array}{l}2.01 \\
(1.39)\end{array}$ & $\begin{array}{l}.08 \\
(.06)\end{array}$ & $\begin{array}{l}-1.48 \\
(1.13)\end{array}$ \\
\hline ED_LABEL $\times$ ED $\rightarrow$ INTOX_BELIEF & $\begin{array}{l}2.51^{*} \\
(1.39)\end{array}$ & $\begin{array}{l}.01 \\
(.06)\end{array}$ & $\begin{array}{l}.55 \\
(1.13)\end{array}$ \\
\hline INTOX $\rightarrow$ ATT_BELIEF & $\begin{array}{l}1.41 \\
(1.75)\end{array}$ & $\begin{array}{l}.01 \\
(.07)\end{array}$ & $\begin{array}{l}3.07^{* *} \\
(1.21)\end{array}$ \\
\hline ED_LABEL $\times$ INTOX $\rightarrow$ ATT_BELIEF & $\begin{array}{l}-.32 \\
(1.75)\end{array}$ & $\begin{array}{l}.09 \\
(.07)\end{array}$ & $\begin{array}{l}1.29 \\
(1.21)\end{array}$ \\
\hline $\mathrm{ED} \rightarrow \mathrm{INTOX} \_$BELIEF $\times$INTOX $\rightarrow$ ATT_BELIEF & $\begin{array}{l}-.69 \\
(1.02)\end{array}$ & $\begin{array}{l}.07 * \\
(.04)\end{array}$ & $\begin{array}{l}.03 \\
(.67)\end{array}$ \\
\hline ED_LABEL $\times$ ED $\rightarrow$ INTOX_BELIEF $\times$ INTOX $\rightarrow$ ATT_BELIEF & $\begin{array}{l}1.97 * * \\
(1.02)\end{array}$ & $\begin{array}{l}.06^{*} \\
(.04)\end{array}$ & $\begin{array}{l}1.24 * \\
(.67)\end{array}$ \\
\hline
\end{tabular}

Notes: ED_LABEL is coded as +.5 in the "Energy Drink" label condition and -.5 when the labels did not mention the presence of an energy drink. $\mathrm{ED} \rightarrow$ INTOX_BELIEF is the mean-centered Belief that "energy drinks increase alcohol intoxication". INTOX $\rightarrow$ ATT_BELIEF is the mean-centered Belief that "alcohol intoxication"...increases impulsiveness (for the risk-taking regression), increases sexual disinhibition (for the sexual self-confidence regression) or weakens reflexes (for the sobering up before driving regression).

${ }^{* * *} p \leq .01, * * p \leq .05,{ }^{*} p \leq .10$.

Intoxication experience had a strongly negative effect on perceived intoxication $(t(148)=-3.09, p=.002)$, indicating that people who are more (vs. less) used to being intoxicated felt less drunk. However, the interaction between experience and the label manipulation was not statistically significant $(t(148)=-1.01, p=.32)$.

Supporting H1b, these results suggest that explicit beliefs increase the placebo effect of Energy Drink labeling on perceived intoxication (consistent with expectancy theory). The fact that intoxication experience did not increase this placebo effect goes against the conditioning theory.

\section{Attitudinal and behavioral effects}

Table 2 shows the results of three separate regressions of risk-taking, sexual self-confidence, and intentions to drive (the attitudinal and behavioral measures). These measures were regressed on the labeling manipulation, the Belief that energy drinks increase alcohol intoxication, the appropriate Belief about the effects of alcohol intoxication on the studied attitude or behavior (i.e. for risk taking: the Belief that alcohol intoxication increases impulsiveness; for sexual confidence: the Belief that alcohol intoxication increases sexual disinhibition; for sobering up before driving: the Belief that alcohol intoxication weakens reflexes), and all interactions.

As shown in Fig. 2, as predicted, the Energy Drink label increased risk-taking $(\mathrm{H} 2 \mathrm{a})$, sexual self-confidence $(\mathrm{H} 3 \mathrm{a})$, and intentions to wait longer before driving (H4a) compared to the control. The labeling manipulation had no significant effect on attractiveness ratings $(p>.80)$, on self-confidence with less attractive women $(p>.50)$, and on intentions to engage in sexually aggressive behaviors $(F(1152)=1.80, p=.18)$. We comment on these non-significant effects in the general discussion.
To illustrate the joint effects of the two "Beliefs" moderators, we developed a new method which extends the Johnson-Neyman technique (Krishna, 2016; Spiller, Fitzsimons, Lynch, \& McClelland, 2013) to a case where a binary manipulated variable is moderated by two (instead of one) continuous variables. Table 2 reports the results of the regressions, and Fig. 3 graphically represents the "significance zones"- the combinations of Beliefs for which the effect of Energy Drink label is statistically significant.

We found the expected three-way interaction between Energy Drink Label, Belief about the effect of energy drinks on alcohol intoxication, and Beliefs about the effect of alcohol intoxication, for all three dependent measures. As predicted (H2b), Fig. 3 (top panel) shows that the Energy Drink label significantly increased risk-taking $(p<.05)$ for participants who strongly believed a) that energy drinks increase alcohol intoxication and b) that alcohol intoxication increases impulsive decision-making. As predicted (H3b), the middle panel of Fig. 3 shows that the Energy Drink label significantly increased sexual self-confidence for participants who strongly believed a) that energy drinks increase alcohol intoxication and b) that alcohol intoxication increases sexual disinhibition. Finally, as predicted (H4b), the bottom panel of Fig. 3 shows that the Energy Drink label significantly increased intentions to sober up before driving for participants who strongly believed a) that energy drinks increase alcohol intoxication and b) that alcohol intoxication weakens reflexes.

In a final set of analyses, we examined the moderating effects of intoxication experience for all three dependent measures. Experience had negative main effects on sexual self-confidence $(t(150)=-3.06, p=.003)$ and intentions to drive $(t(150)=-3.04, \quad p=.003)$, but not on risk-taking $(\mathrm{p}>$.90). Experience did not interact with Energy Drink label for any of the three behaviors $(t(150)=-1.09, p=.28$ for risk taking, $t(150)=-.74, p=.46$ for sexual self-confidence, and $t(150)=-$ 

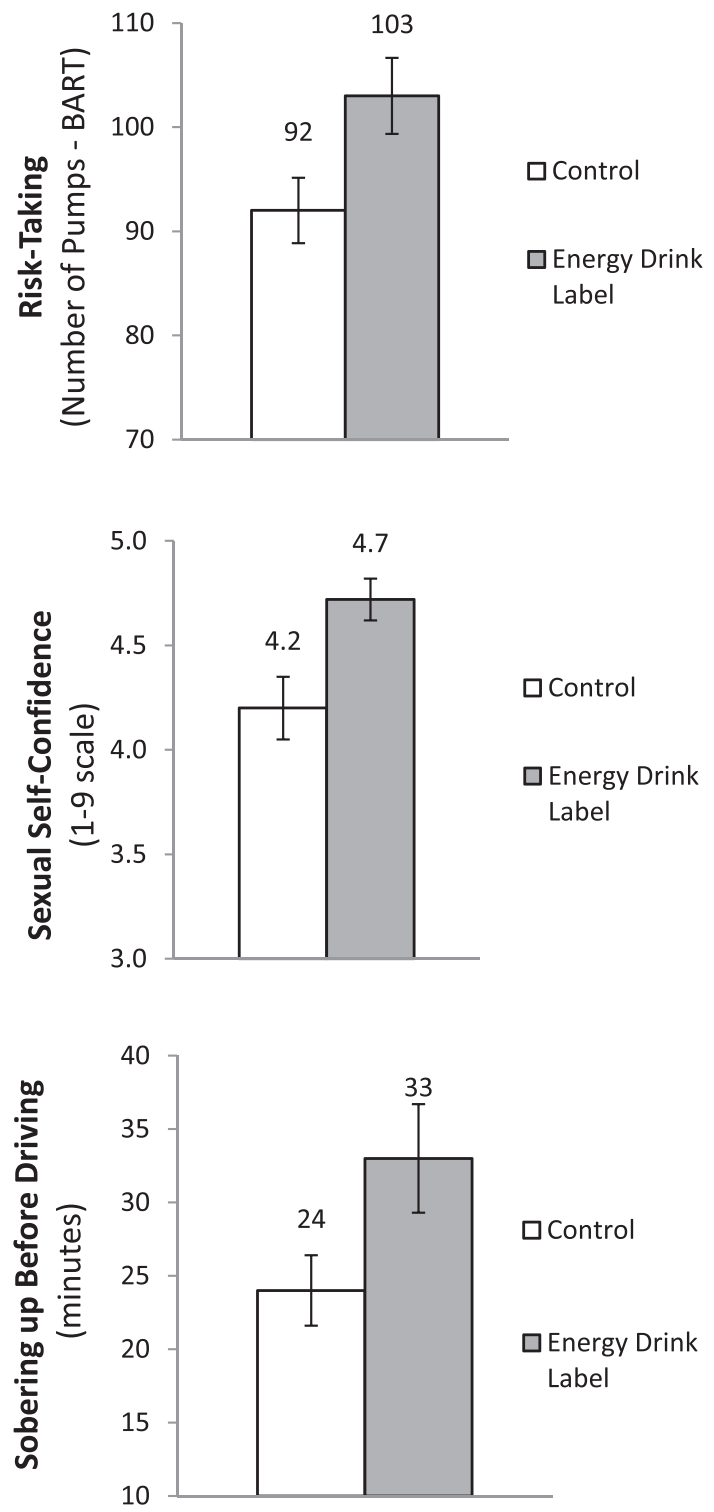

Fig. 2. Attitudinal and behavioral effects of energy drink label. Note: After drinking alcohol mixed with an energy drink, participants who were given the drink with an Energy Drink label took more risk (more pumps in the Balloon Analogue Risk Task), were more sexually self-confident (higher intentions to chat up attractive women, and higher confidence that attractive women will accept the advances), and were willing to wait longer before driving. Error bars denote standard errors.

1.46, $p=.15$ for intentions to drive), speaking against the prediction of a conditioning explanation of these placebo effects.

\section{Discussion}

We find that young males feel more intoxicated, are more sexually self-confident, take more risks, but intend to wait longer before driving after drinking a cocktail of vodka, energy drink, and fruit juices labeled as a "Vodka Red-Bull" cocktail vs. a "Vodka" or an "Exotic fruit" cocktail. We also find that these effects are independent of past intoxication experience but are stronger for people who believe that energy drinks increase alcohol intoxication and that alcohol intoxication increases impulsiveness, removes sexual inhibition, and weakens reflexes.

\section{Public policy implications}

Although our research relies on a single study and further research is necessary to verify that our results replicate for ad-libitum consumption, it suggests that energy drinks can boost perceived alcohol intoxication through placebo effects-the opposite of the current FDA theory that energy drinks mask alcohol intoxication. Importantly, we show that these placebo effects can be easily manipulated by people buying drinks for others if they selectively emphasize the presence of an energy drink when describing the cocktail.

Our findings suggest that policy makers, food safety agencies, and industry associations should re-examine the regulation and codes of conduct regarding the advertising and labeling of energy drinks based on their psychological — and not just pharmacological — effects. In addition, assessing the harm caused by energy drinks and their specific ingredients (e.g., caffeine, sugar, or ginseng), should consider their effects when mixed with alcohol and not just when consumed alone. Given their effects on sexual disinhibition and risk-taking, it may be advisable to restrict the sale of cocktails mixing alcohol and energy drinks, or the availability of both beverages in the same venue, in environments associated with sexual misconduct (e.g., college campuses) and gambling. Conversely, our results suggest that communicating about the danger of driving after AMED consumption in bars or clubs should not be the priority.

More generally, consumer protection agencies like the Federal Trade Commission and advocacy groups like Mothers Against Drunk Driving should consider refocusing their attention. Rather than highlighting the dangers of driving after AMED consumption, which people are already aware of, they should criticize, or even consider banning energy drink marketers from touting the disinhibiting effect of their products (as in Red Bull's "give you wing" campaign, or Monster's "Unleash the beast" campaign), which can turn an innocuous ingredient into an active placebo.

\section{Limitations and theoretical implications}

Our results show that placebo effects can rely solely on explicit beliefs, even when those beliefs are not backed or reinforced by experience. Consistent with the "expectancy" theory of placebo effects, the effects of AMED labels on perceived intoxication, attitudes and behaviors were moderated by explicit beliefs about AMEDs and alcohol intoxication. Contrary to the "conditioning" theory, these effects were not strengthened by intoxication experience.

We speculate that beliefs about the boosting effects of energy drinks on alcohol intoxication are shaped by marketing and media messages about the disinhibiting effect of energy drinks, especially when mixed with alcohol. Still, we did not formally test this hypothesis. In future research, it would be interesting to measure participants' exposure to advertising 

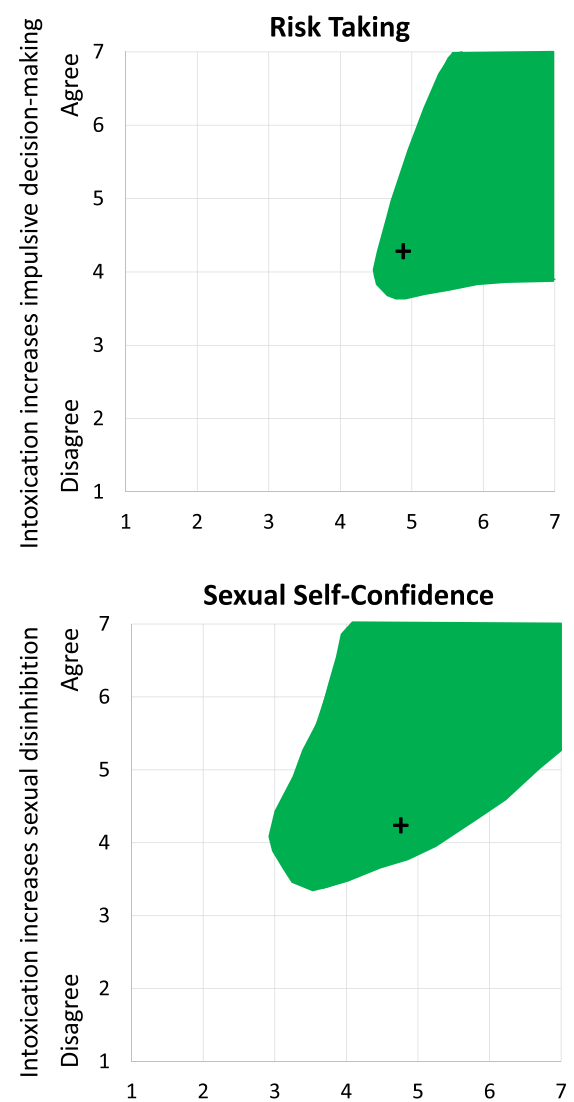

Combination of beliefs for which Energy Drink Label significantly increases the dependent variable $(p<.05)$

$+\quad$ Mean belief level

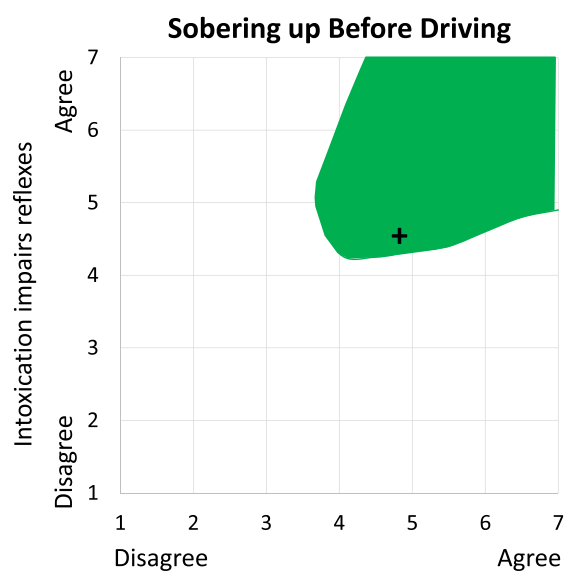

Energy drinks increase alcohol intoxication

Fig. 3. Significance zones for the effects of energy drink label on attitudes and behavior. Note: The significance zone was determined by estimating the regressions shown in Table 2 with different combinations of values for ED $\rightarrow$ INTOX_BELIEF and INTOX $\rightarrow$ ATT_BELIEF.

and sales promotions, both on and off premises and test which type of exposure strengthens marketing placebo effects. It would also be interesting to study whether AMED placebo effects replicate with other brands of energy drinks, which rely on other communication strategies than Red Bull.

Perhaps surprisingly, we found that AMED labels decreased intentions to drive after drinking alcohol mixed with an energy drink. Although this finding is consistent with research suggesting that feeling intoxicated leads to low driving intentions (Beirness, 1987; Quinn \& Fromme, 2012), it is inconsistent with correlational studies showing that AMED consumption is associated with driving accidents (Howland \& Rohsenow, 2013). This inconsistency may be explained by potential demand effects in our study, although we took care to measure intentions to drive before measuring perceived intoxication. It may also be explained by self-selection in the correlational studies: AMED drinkers may be more prone to reckless driving. Future research should investigate the effect of 
AMED labels on driving intentions versus behavior, perhaps with computer-based driving simulations (Calhoun, Carvalho, Astur, \& Pearlson, 2005).

An important question for future research is to better understand the process underlying placebo effects. On the one hand, Moss and Albery (2009) argue that placebo effects rely on the activation of mental representations that make certain attitudes and behaviors more accessible. On the other hand, Shiv et al. (2005) argue that placebo effects also modify people's subjective and sensory experiences of products. We found that Energy Drink labels made people feel more intoxicated, which is a sensory experience. However, we relied on self-reports. Future research should therefore test the impact of AMED labels on direct sensory or somatosensory measures such as dizziness (e.g. walking along a line).

Past research has argued that motivation and desirability play a key role in medical and marketing placebo effects (Jensen \& Karoly, 1991; Vase, Robinson, Verne, \& Price, 2003). Irmak et al. (2005) found that participants felt energized after drinking a placebo drink claiming to be energizing, but only when they desired this effect. Our study provides some elements suggesting that desirability also played a role. We found that the labeling manipulation significantly impacted participants' sexual self-confidence with attractive women (a possibly desirable effect of alcohol intoxication), but did not significantly impact self-confidence with less attractive women, and more importantly, their sexual aggressiveness (a possibly undesirable effect of alcohol intoxication). Future research should further explore the role of motivation in AMED placebo effects.

Future research should also test if our findings replicate among different populations (e.g., females of the same age, older males), and among onlookers versus imbibers. We advocate more research on placebo effects created by marketing actions like price, logos, labels and advertising; and on alcohol and AMED effects. While there is much focus on food intake due to the health consequences of obesity, there is comparatively little consumer research on alcohol, despite its significant negative consequences.

\section{Appendix A. Supplementary data}

Supplementary data to this article can be found online at http://dx.doi.org/10.1016/j.jcps.2017.03.003.

\section{References}

Ariely, D., \& Loewenstein, G. (2006). The heat of the moment: The effect of sexual arousal on sexual decision making. Journal of Behavioral Decision Making, 19, 87-98.

Bègue, L., Bushman, B. J., Zerhouni, O., Subra, B., \& Ourabah, M. (2013). 'Beauty is in the eye of the beer holder': People who think they are drunk also think they are attractive. British Journal of Psychology, 104, 225-234.

Bègue, L., Subra, B., Arvers, P., Muller, D., Bricout, V., \& Zorman, M. (2009). A message in a bottle: Extrapharmacological effects of alcohol on aggression. Journal of Experimental Social Psychology, 45, 137-142.

Beirness, D. J. (1987). Self-estimates of blood alcohol concentration in drinking-driving context. Drug and Alcohol Dependence, 19, 79-90.
Benson, S., Verster, J. C., Alford, C., \& Scholey, A. (2014). Effects of mixing alcohol with caffeinated beverages on subjective intoxication: A systematic review and meta-analysis. Neuroscience and Biobehavioral Reviews, 47, $16-21$.

Brasel, S. A., \& Gips, J. (2011). Red Bull "gives you wings" for better or worse: A double-edged impact of brand exposure on consumer performance. Journal of Consumer Psychology, 21, 57-64.

Brown, S. A., Christiansen, B. A., \& Goldman, M. S. (1987). The Alcohol Expectancy Questionnaire: An instrument for the assessment of adolescent and adult alcohol expectancies. Journal of Studies on Alcohol, 48, 483-491.

Bush, K., Kivlahan, D. R., McDonell, M. B., Fihn, S. D., \& Bradley, K. A. (1998). The AUDIT alcohol consumption questions (AUDIT-C): An effective brief screening test for problem drinking. Archives of Internal Medicine, 158, 1789-1795.

Calhoun, V. D., Carvalho, K., Astur, R., \& Pearlson, G. D. (2005). Using virtual reality to study alcohol intoxication effects on the neural correlates of simulated driving. Applied Psychophysiology and Biofeedback, 30, 285-306.

Careathers v. Red Bull GmBh (2016). U.S. Civil Court Records for the Southern District of New York.

Colloca, L., Petrovic, P., Wager, T. D., Ingvar, M., \& Benedetti, F. (2010). How the number of learning trials affects placebo and nocebo responses. Pain ${ }^{\circledR}$, $151,430-439$.

Corazzini, L., Filippin, A., \& Vanin, P. (2014). Economic behavior under alcohol influence: An experiment on time, risk, and social preferences. Quaderni - working paper DSE $N^{\circ} 944$.

EFSA (2015). Scientific opinion on the safety of caffeine. EFSA Journal, 13, 4102.

FDA (2010). FDA warning letters issued to four makers of caffeinated alcoholic beverages.

Fromme, K., Katz, E., \& D’Amico, E. (1997a). Effects of alcohol intoxication on the perceived consequences of risk taking. Experimental and Clinical Psychopharmacology, 5, 14.

Fromme, K., Katz, E. C., \& Rivet, K. (1997b). Outcome expectancies and risktaking behavior. Cognitive Therapy and Research, 21, 421-442.

George, W. H., \& Stoner, S. A. (2000). Understanding acute alcohol effects on sexual behavior. Annual Review of Sex Research, 11, 92-124.

Howland, J., \& Rohsenow, D. J. (2013). Risks of energy drinks mixed with alcohol. JAMA, 309, 245-246.

Hull, J. G., \& Bond, C. F. (1986). Social and behavioral consequences of alcohol consumption and expectancy: A meta-analysis. Psychological Bulletin, 99, 347.

Irmak, C., Block, L., \& Fitzsimons, G. J. (2005). The placebo effect in marketing: Sometimes you just have to want it to work. Journal of Marketing Research, 42, 406-409.

Jensen, M. P., \& Karoly, P. (1991). Motivation and expectancy factors in symptom perception: A laboratory study of the placebo effect. Psychosomatic Medicine, 53, 144-152.

Krishna, A. (2016). A clearer spotlight on spotlight: Understanding, conducting and reporting. Journal of Consumer Psychology, 26(3), 315-324.

Leigh, B. C., \& Stacy, A. W. (1993). Alcohol outcome expectancies: Scale construction and predictive utility in higher order confirmatory models. Psychological Assessment, 5, 216.

Lejuez, C. W., Read, J. P., Kahler, C. W., Richards, J. B., Ramsey, S. E., Stuart, G. L., ... Brown, R. A. (2002). Evaluation of a behavioral measure of risk taking: The Balloon Analogue Risk Task (BART). Journal of Experimental Psychology. Applied, 8, 75.

Marczinski, C. A., Fillmore, M. T., Bardgett, M. E., \& Howard, M. A. (2011). Effects of energy drinks mixed with alcohol on behavioral control: Risks for college students consuming trendy cocktails. Alcoholism: Clinical and Experimental Research, 35, 1282-1292.

Miller, P. (2013). Energy drinks and alcohol: Research supported by industry may be downplaying harms. BMJ: British Medical Journal, 347.

Moss, A. C., \& Albery, I. P. (2009). A dual-process model of the alcoholbehavior link for social drinking. Psychological Bulletin, 135, 516.

NIAAA-NIH (2014). Cocktail content calculator. Rethinking drinking.

Peacock, A., Bruno, R., \& Martin, F. H. (2012). The subjective physiological, psychological, and behavioral risk-taking consequences of alcohol and energy drink co-ingestion. Alcoholism: Clinical and Experimental Research, 36, 2008-2015. 
Peacock, A., Bruno, R., \& Martin, F. H. (2013). Patterns of use and motivations for consuming alcohol mixed with energy drinks. Psychology of Addictive Behaviors, 27, 202.

Plassmann, H., \& Wagner, T. (2014). How expectancies shape consumption experiences. In S. D. Preston, M. L. Kringelbach, \& B. Knutson (Eds.), The interdisciplinary science of consumption. The MIT Press.

Quinn, P. D., \& Fromme, K. (2012). Event-level associations between objective and subjective alcohol intoxication and driving after drinking across the college years. Psychology of Addictive Behaviors, 26, 384.

Saunders, J. B., Aasland, O. G., Babor, T. F., \& Grant, M. (1993). Development of the alcohol use disorders identification test (AUDIT): WHO collaborative project on early detection of persons with harmful alcohol consumption-II. Addiction, 88, 791-804

Shiv, B., Carmon, Z., \& Ariely, D. (2005). Placebo effects of marketing actions: Consumers may get what they pay for. Journal of Marketing Research, 42, $383-393$.

Skeen, M. P., \& Glenn, L. L. (2011). Imaginary link between alcoholism and energy drinks. Alcoholism: Clinical and Experimental Research, 35, 1375-1376.
Spiller, S. A., Fitzsimons, G. J., Lynch, J. G., Jr., \& McClelland, G. H. (2013). Spotlights, floodlights, and the magic number zero: Simple effects tests in moderated regression. Journal of Marketing Research, 50, 277-288.

Stewart-Williams, S., \& Podd, J. (2004). The placebo effect: Dissolving the expectancy versus conditioning debate. Psychological Bulletin, 130, 324.

Vase, L., Robinson, M. E., Verne, G. N., \& Price, D. D. (2003). The contributions of suggestion, desire, and expectation to placebo effects in irritable bowel syndrome patients: An empirical investigation. Pain, 105, 17-25.

Verster, J. C., Aufricht, C., \& Alford, C. (2012). Energy drinks mixed with alcohol: Misconceptions, myths, and facts. International Journal of General Medicine, 5, 187-198.

Young, R. M., \& Knight, R. G. (1989). The Drinking Expectancy Questionnaire: A revised measure of alcohol-related beliefs. Journal of Psychopathology and Behavioral Assessment, 11, 99-112. 